As conferências do Conselho Brasileiro de Oftalmologia, proferidas por eminentes mestres da Oftalmologia nacional, tornaram-se tradicionais desde quando criadas, há já quase vinte anos, passando a representar um dos pontos altos de nossos Congressos. Não só homenageiam seus apresentadores, distingüindo-os entre tantos outros também muito capacitados ao oferecimento dessas aulas magistrais, como presenteiam os ouvintes pelo vigor dos temas escolhidos e pela qualidade em seus desenvolvimentos. Faltava, apenas, que também se garantisse a preservação dessas culminâncias da oftalmologia brasileira, em que talentos didáticos, experiências científicas e oportunidades de expressão convergem em momentos únicos. Então, doravante, os Arquivos Brasileiros de Oftalmologia propõem-se a estender a seus leitores e àqueles que não tiveram o privilégio de presenciar as conferências, seus conteúdos essenciais, começando com a sobre "Doenças da mácula", proferida por Marcos P. Ávila, Presidente do C.B.O. no biênio 1999-2001.

E começa otimamente, porque Marcos Ávila, bem a seu estilo, não se detem no trivial, nem pensa em termos comuns, vai além: de sua própria iniciativa, mas talvez já criando um fato novo, disponibiliza com a forma impressa da conferência sua edição em CD-ROM, cuja distribuição é agora feita com a da revista. Em nome de todos que se beneficiam com essa gentileza, os agradecimentos pela idéia e por sua concretização.

Finalmente, resgatando as conferências anteriores, em reconhecimento de seus valores, são listados os assuntos, apresentadores, locais, datas e eventos (em 1990 e 1992 elas ocorreram também nos Congressos Brasileiros de Prevenção da Cegueira e Reabilitação Visual), como resenha histórica, singela mas merecida.

\begin{tabular}{|c|c|c|c|}
\hline Ano & Local & Congresso & Conferencista / conferência \\
\hline 1985 & São Paulo & XXIII Brasileiro & $\begin{array}{l}\text { Nassim da Silveira Calixto } \\
\text { Síndrome da membrana endotelial irido-corneana }\end{array}$ \\
\hline 1987 & Curitiba & XXIV Brasileiro & $\begin{array}{l}\text { Jorge Alberto Fonseca Caldeira } \\
\text { Cirurgia dos músculos oblíquos do olho: situação atual e perspectivas futuras }\end{array}$ \\
\hline 1989 & Rio de Janeiro & XXV Brasileiro & $\begin{array}{l}\text { Newton Kara José } \\
\text { Responsabilidade do Oftalmologista e das Associações na Prevenção da Cegueira }\end{array}$ \\
\hline 1990 & Salvador & IX Prevenção & $\begin{array}{l}\text { Hilton Ribeiro da Rocha } \\
\text { Histórico da situação atual e futuro da reabilitação }\end{array}$ \\
\hline 1991 & Belo Horizonte & XXVI Brasileiro & $\begin{array}{l}\text { João Orlando Ribeiro Gonçalves } \\
\text { Leucocorias }\end{array}$ \\
\hline 1992 & Manaus & X Prevenção & $\begin{array}{l}\text { Rubens Belfort Mattos } \\
\text { Causas de cegueira nos Indígenas Brasileiros }\end{array}$ \\
\hline 1993 & Porto Alegre & XXVII Brasileiro & $\begin{array}{l}\text { Fernando Oréfice } \\
\text { Toxocaríase Ocular e sua Epidemiologia }\end{array}$ \\
\hline 1995 & Salvador & XXVIII Brasileiro & $\begin{array}{l}\text { Rubens Belfort Júnior } \\
\text { Ensino de Graduação, Especialização, Pós-Graduação e Pesquisa em Oftalmologia no Brasil }\end{array}$ \\
\hline 1997 & Goiânia & XXIX Brasileiro & $\begin{array}{l}\text { Adalmir Morterá Dantas } \\
\text { Neuropatia Óptica Isquêmica Anterior }\end{array}$ \\
\hline 1999 & Recife & XXX Brasileiro & $\begin{array}{l}\text { Jacó Lavinsky } \\
\text { Retina: Presente e Futuro }\end{array}$ \\
\hline 2001 & São Paulo & XXXI Brasileiro & $\begin{array}{l}\text { Geraldo Vicente de Almeida } \\
2001 \text { - A Odisséia do Glaucoma }\end{array}$ \\
\hline 2003 & Salvador & XXXII Brasileiro & $\begin{array}{l}\text { Marcos Pereira Ávila } \\
\text { A Retina no século XXI }\end{array}$ \\
\hline
\end{tabular}




\title{
A Retina no Século XXI
}

\author{
Marcos Ávila **
}

Este texto pretende fazer a releitura dos grandes marcos da retinologia ao longo dos tempos, remetendo-se a um passado distante, detendo-se no presente ano de 2003 e deslocando-se ao futuro, no ano 2020 , marco teórico da visão $20 / 20$ ou visão total.

Pretende enfatizar pessoas e técnicas que se imortalizaram, a despeito de haver sido feito ou não o reconhecimento formal dos atos e dos fatos, principalmente nos últimos 50 anos. Avaliando a evolução do exame da retina e a introdução do laser no tratamento; ampliando a abordagem da retinopatia diabética; analisando os avanços no conhecimento da degeneração macular relacionada à idade, do descolamento de retina e do buraco macular, será revisada a história do desenvolvimento tecnológico da retinologia.

\section{O Exame da Retina}

A oftalmoscopia, introduzida em 1851, por Helmholtz, é até hoje um dos capítulos mais envolventes da moderna oftalmologia. Na era pré-oftalmoscópica foram feitos relatos de várias experiências sobre o fundo ocular, destacando-se, por pitoresca e extravagante, a descrição de Jean Mèry, em 1704, quando, para estudar os movimentos da pupila, mergulhou um gato no lago. Entrando em anoxia, o animal sofreu grande dilatação pupilar. O poder dióptrico do olho foi neutralizado pela presença da lâmina d'água, principalmente da córnea, favorecendo a observação e descrição, pela primeira vez, dos vasos da retina.

Considerado como o pai da oftalmoscopia, Hermann Von Helmholtz apresentou o seu aparelho, pela primeira vez, em 1851. Dois anos depois, a Europa, nos primeiros momentos de seu processo de industrialização, teve dificuldade para atender à demanda do mercado pelo aparelho, em todo o mundo. Dez anos mais tarde (1861) Girard Teulon introduziu o oftalmoscópio binocular, que embora sem luz elétrica, utilizava através de espelhos, o reflexo da luz solar sobre a retina. Somente em 1885 foi introduzido o uso da luz elétrica na realização do exame, por Dennet.

A oftalmoscopia deve muito também a Charles Schepens, profissional belga que fez parte da resistência contra a inva-

\footnotetext{
* Proferida no dia 10 de setembro de 2003 durante o XXXII Congresso Brasileiro de Oftalmologia, Salvador, BA.

** Professor e Chefe do Serviço de Oftalmologia da Faculdade de Medicina da Universidade Federal de Goiás, Chefe do CEROF - Centro de Referência em Oftalmologia da UFG, Presidente do Conselho Brasileiro de Oftalmologia - 1999-2001.

e-mail: retina@cbco.com.br
}

são alemã e, fugindo da prisão, se refugiou na Inglaterra. Utilizando-se de pedaços de armamento bélico, desenvolveu o moderno oftalmoscópio binocular indireto. Posteriormente, após ter se mudado para Boston, nos EUA, apresentou à comunidade científica em 1947 o instrumento que utiliza os mesmos princípios até hoje, 56 anos depois, tendo apenas o seu desenho modificado. Aceitando-se que no ano 2020 a clínica permanecerá soberana no diagnóstico, a oftalmoscopia continuará sendo o exame mais importante na observação das alterações que ocorrem no fundo ocular.

Em 1901 foram feitas as primeiras fotografias do fundo ocular, sem o registro exato de sua autoria, talvez por não se antever que as mesmas se perenizariam na história. E, 60 anos depois, com a introdução da técnica da angiofluoresceinografia, por Novotny e Alvis, chegou-se a este importante instrumento de observação das estruturas e tecidos in vivo. $\mathrm{O}$ mérito desta contribuição foi devidamente reconhecido em 1965, através do tratado de Donald Gass, em Miami, nos EUA, como um dos exames mais completos do corpo humano. A injeção de fluoresceína sódica, como corante, feita em veia periférica, permite a captação de imagens do fundo ocular e o seu armazenamento em filme ou meios eletrônicos. Tornam-se assim possíveis a demonstração e o tratamento de lesões da coróide, doenças do epitélio pigmentar e deformações anatômicas nas superfícies anterior e posterior da retina, de origem adquirida ou hereditária. Podem ser feitas inúmeras combinações diagnósticas na interpretação da angiofluoresceinografia, através de fatores associados à sua propriedade de causar alterações na fluorescência (aumento, diminuição ou bloqueio). Esta técnica foi introduzida no Brasil (Minas Gerais), por Christiano Barsante, em 1968.

A oftalmologia foi pioneira também na introdução da biomicroscopia, em 1911, por Gullstrand, o único oftalmologista a ganhar o prêmio Nobel. Posteriormente, outras especialidades, como a ginecologia, passaram a utilizá-la. Em 1941, a introdução da lente de Hruby estimulou o uso da biomicroscopia do fundo ocular, considerado hoje como importante recurso, capaz de detectar, com a minúcia necessária, lesões que aparecem na retina ou na coróide. Usando-se a lâmpada de fenda é possível observar estas alterações através de várias lentes de contato ou de lentes de condensação de não contato, com variações de 60 a 90 dioptrias.

A eletrofisiologia ocular, exame atribuído a Karpe, em 1945, foi introduzida no Brasil por Queiroga, Hilton Rocha e Elisabeto Gonçalves entre os anos de 1953 e 1968. Posteriormente, aquele grupo publicou importantes trabalhos, incluindo os achados eletrorretinográficos característicos da DUSN (neu- 


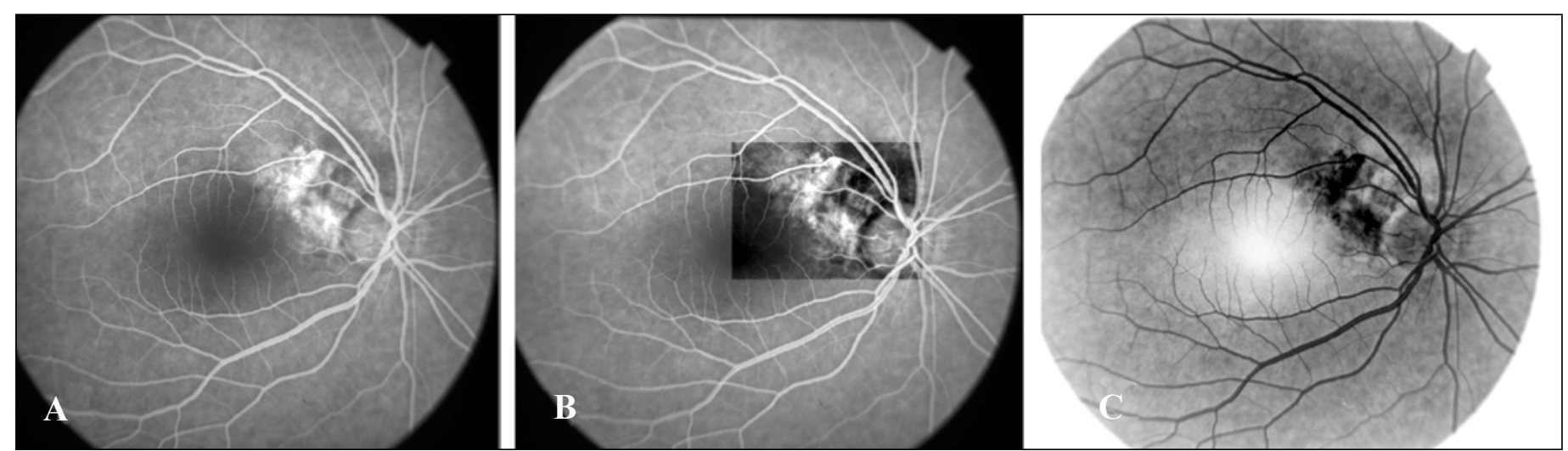

Figura 1 - Angiofluoresceinografia. Extravasamento sub-retiniano temporal superior ao nervo óptico: A) Imagem convencional; B) Box de melhoramento de imagem; C) Transposição para o negativo

ropatia unilateral difusa aguda). Hoje, o eletrerretinograma, o eletrooculograma e o potencial visual evocado são importantes recursos na avaliação do nervo e vias ópticas, das doenças hereditárias e alterações isquêmicas da retina.

Mantendo sua característica pioneira, a oftalmologia introduziu também o uso da ecografia, em 1956, através de Mundt e Hughes, exame que mostra, com exatidão, a interface vítreoretiniana, evidenciando o descolamento da retina, áreas de tração vítreo-retiniana, tumores intra-oculares ou alterações na espessura da coróide em situação de opacidades de meios. O desenvolvimento da ecografia fez surgir, em 1980, a biomicroscopia ultra-sônica, capaz de visualizar, com nitidez, pequenas alterações nas estruturas anteriores do globo ocular, impossíveis de serem observadas pelas técnicas de oftalmoscopia e biomicroscopia.

$\mathrm{O}$ surgimento dos computadores pessoais deu origem à era digital, viabilizando, em pouco tempo, métodos diagnósticos avançados, exames somente possíveis com o uso da tecnologia de captação de imagens. Foram revigoradas antigas técnicas como eletrofisiologia, ecografia digital, biomicroscopia ultra-sônica e a fotografia do fundus ocular.

O marco da era digital, no início dos anos 80 , foram as câmeras de vídeo que captam as imagens do fundo ocular, subseqüentemente digitalizadas e armazenadas em meios eletrônicos. As imagens produzidas pela angiofluoresceinografia podem ser melhoradas através de softwares, favorecendo a sua interpretação (Figura 1).

A era digital possibilitou ainda o uso de corantes de baixa fluorescência como a indocianina verde, que necessita de câmera de vídeo de alto poder para captação de imagens com baixa luminosidade. Quando introduzimos o exame no Brasil, em 1994, conseguimos identificar a presença de membranas neovasculares sub-retinianas (MNSR) não visualizadas pela angiofluoresceinografia (Figura 2).

A era digital viabilizou o uso do Scanning Laser Ophthalmoscope ( $S L O$ ), aparelho que possibilita a realização de microperimetria, sob visualização direta de cada ponto da retina, identificando aqueles sem visão, levando ao mapeamento exato de escotomas em pacientes com lesão macular; possibilita a visumetria, ou avaliação do potencial de visão central; e possibilita a realização de angiografia digital de alta resolução e velocidade, usando a fluoresceína e a indocianina verde. $\mathrm{O}$ aparelho foi introduzido no País pelo nosso grupo, em 1994, quando descrevemos a sua utilidade em várias maculopatias, incluindo a localização de parasitas intra-oculares (Figura 3).

A era digital permitiu a introdução de aparelhos capazes

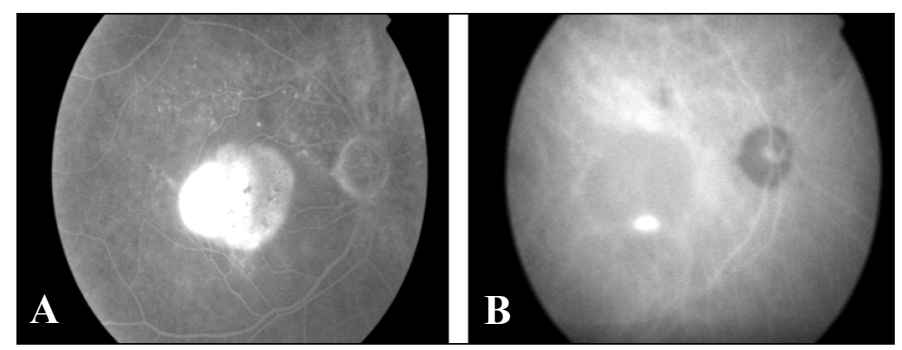

Figura 2 - A) Angiofluoresceinografia: Descolamento do epitélio pigmentar (DEP) e membrana neovascular sub-retiniana (MNSR) oculta; B) Videoangiografia Digital com Indocianina Verde: MNSR bem definida na margem inferior do DEP

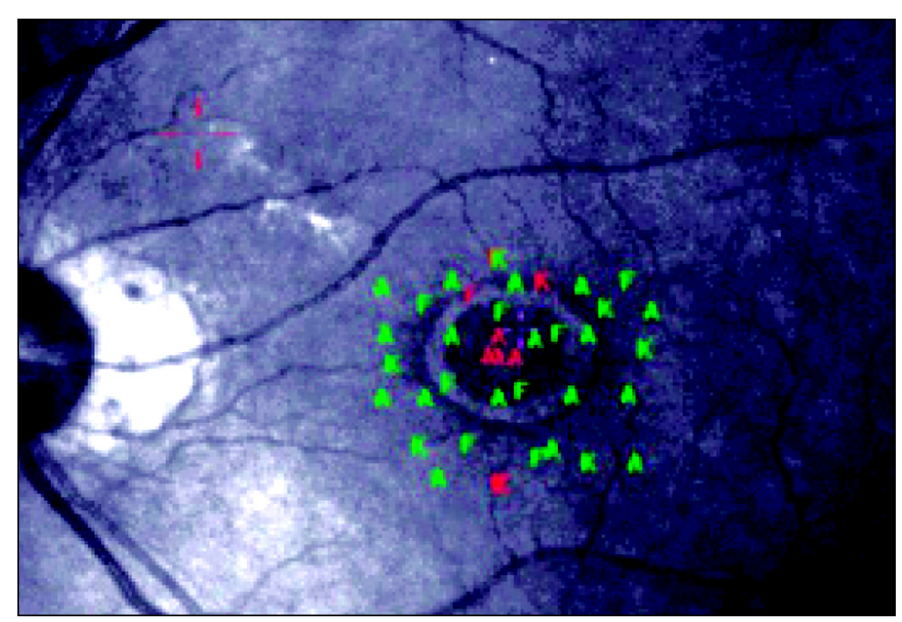

Figura 3 - Scanning Laser Ophthalmoscope: Microperimetria demonstrando pontos de escotoma (pontos vermelhos) em paciente com buraco de mácula 
de medir a espessura retiniana, como o RTA (Retinal Thickness Analyzer), utilizado por nosso grupo para viabilizar a realização de tese de doutoramento do Dr. Eduardo Damasceno, aprovada pela Universidade Federal do Rio de Janeiro, no final de 2002, que se utiliza da medida da espessura da retina (Figura 4) para propor uma nova classificação do edema macular na retinopatia diabética. O Tomógrafo de Coerência óptica (OCT) é outro aparelho capaz de medir a espessura retiniana e as alterações anatômico-estruturais do nervo óptico a da mácula central (Figura 5).

Um novo aparelho, o HRT, de recente lançamento, utiliza a tecnologia digital para fazer a angiografia em alta velocida$d e$, útil para melhor verificação da fase precoce do angiograma. Outro lançamento recente é o RETCAN, que possibilita a avaliação de toda a retina (central, periferia média e periferia mais extrema), através de uma câmera que registra imagens de grande angular, procedimento útil no estudo de tumores e em pacientes com isquemia periférica.

Espera-se que, entre 2003 e o ano 20/20 (2020), seja registrado um intenso desenvolvimento tecnológico que otimize o

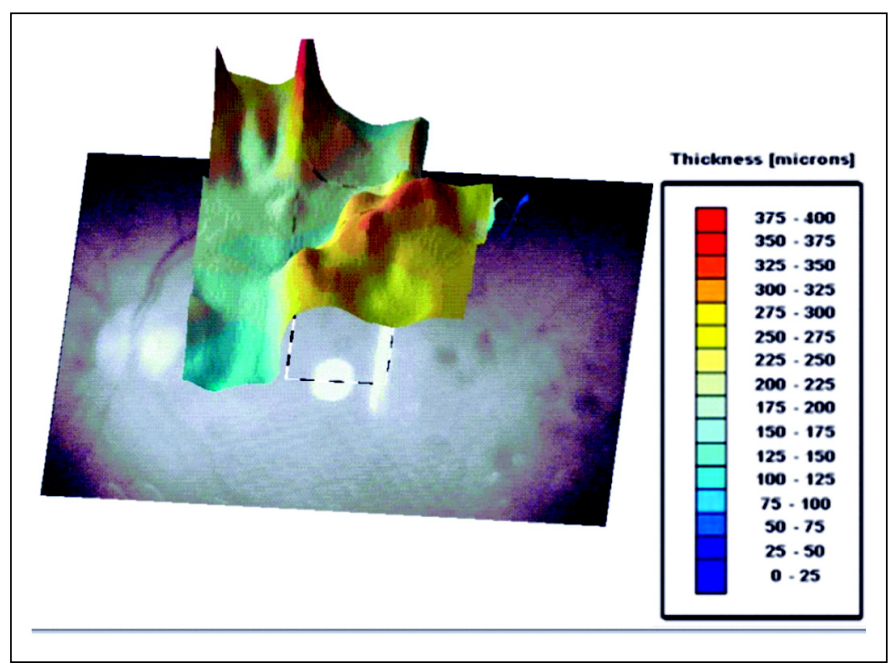

Figura 4 - Retinal Thickeness Analyzer (RTA): paciente com edema macular diabético, com aumento da espessura macular (330 micra). Medida de pacientes normais até 180 micra

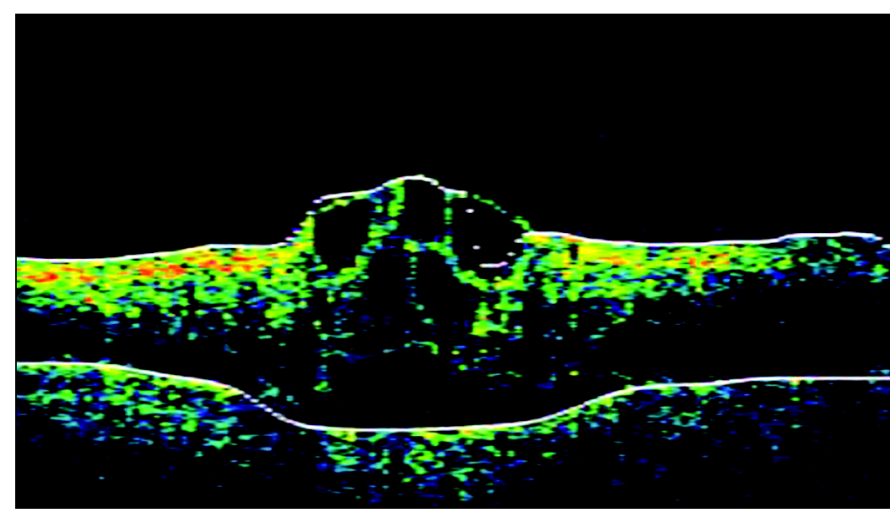

Figura 5 - Optical Coherence Tomography (OCT): Edema Macular Cistóide diagnóstico precoce e o conseqüente tratamento oportuno. O melhoramento dos softwares, a ampliação do uso da linguagem digital e a configuração de redes devem permitir a exploração do âmago de cada pixel, construindo imagens cada vez melhores e com mais informações para o controle das doenças da retina e do vítreo, passo definitivo para o desenvolvimento da teleoftalmologia. Trabalhando em conjunto com Jorge Fraga, Alexandre Taleb e Marcos Batalha, conseguimos colocar em rede imagens digitais da retina e de todo o globo ocular, originadas em vários aparelhos.

\section{A Retina e o Laser}

A oftalmologia tem novo motivo de orgulho por haver sido a primeira especialidade médica a utilizar o laser para tratamento de humanos. Ainda nos anos $400 \mathrm{dC}$, a humanidade tem seu primeiro relato de lesão térmica da retina, quando Platão aventa a hipótese de danos causados à retina de pessoas que olhavam fixamente para eclipses.

A origem do conceito do laser (Light Amplification by Stimulated Emission of Radiation) é atribuída a Einstein (prêmio Nobel) na identificação do fenômeno por ele denominado emissão estimulada, resultante da estimulação de fótons.

Nos anos 50, Meyer-Schwickerath introduziu a fotocoagulação no tratamento das doenças da retina, utilizando a luz solar. O equipamento, de grande engenhosidade, usava o oftalmoscópio direto e provocava queimaduras retinianas direcionadas e específicas. Na década de 60, o mesmo Schwickerath desenvolveu o primeiro fotocoagulador, utilizando o arco de xenônio, aparelho que foi produzido na Alemanha, pela companhia Zeiss Optical.

Em 1961 Koester e Campbell usaram o protótipo de laser de rubi para fotocoagulação de tumor de retina em humano. Gosto de denominar as décadas de 60 e 70 como a era da retinopatia diabética, quando Francis L'Esperance, em 1965, publicou os primeiros resultados no tratamento da retinopatia diabética usando o laser de rubi e, em 1968, o mesmo L'Esperance tratou o primeiro paciente humano com laser de argônio. Em 1971 foi iniciada uma série de estudos clínicos nos EUA e na Europa, avaliando o benefício do laser de argônio no tratamento de retinopatia diabética, quando comparado com a história natural da doença. Mais uma vez a oftalmologia brasileira se apresentou na vanguarda da introdução de modernas tecnologias quando, em 1975, Suel Abujamra e Valter Justa introduziram, no Brasil, o uso do laser de argônio.

$\mathrm{Na}$ década de 80 teve início o uso da fotocoagulação macular seletiva, em decorrência dos trabalhos desenvolvidos pela Retina Foundation, em Boston, onde vários pesquisadores, dentre os quais me incluo, começaram a perceber que a luz azul, contida no laser de argônio de maior uso na ocasião, provocava lesões maculares, decorrentes da absorção da luz azul pela xantofila existente nas camadas superficiais da retina, na área macular. A eliminação da luz azul do argônio, através de prismas ou filtros, levou à utilização da luz verde do argônio e, posteriormente, das luzes amarela, verde e, principalmente, da luz vermelha do criptônio direcionadas aos pig- 
mentos alvo (melanina e hemoglobina). O estudo da fotocoagulação macular seletiva propiciou a publicação de uma série de trabalhos entre 1980 e 1985 , em várias revistas de grande impacto científico naquela época.

Nos anos 90 houve grande mudança nas fontes que geram o laser. O potencial de obtenção de laser está contido em qualquer substância, sendo utilizados, nos anos 70 e 80, o laser obtido com os gases ionizáveis (principalmente argônio e criptônio), contidos nos chamados tubos, estimulados por uma grande fonte que provoca a excitação da molécula do gás, levando à indução de uma luz emitida de forma unidirecional e coerente. Utilizavam-se os gases ionizáveis pela facilidade de excitação das suas moléculas. Descobriu-se que substâncias no estado sólido (principalmente os cristais) eram capazes também de produzir o mesmo efeito, substituindo-se o grande tubo por pequenas quantidades da substância (de 6 a $10 \mathrm{~cm}$ ) que propiciavam o mesmo efeito diante de uma pequena fonte de excitação (uma simples lâmpada de projetor de slide, por exemplo). Surgiram assim, os lasers mais comuns como o neodimium-YAG de dupla freqüência. Na mesma época surgiu o laser de diodo e, ao final dos anos 90, a fotocoagulação macular seletiva, em sua segunda fase.

O grupo de Elias Reichel introduziu, em Boston, a termoterapia transpupilar (TTT), que até o presente não apresentou resultados terapêuticos confirmados por estudos controlados. Entretanto, na mesma época, os pigmentos naturais do olho (melanina e hemoglobina) foram substituídos por pigmentos artificiais que, seletivamente, se alojam em tecidos alvo para fotocoagulação (principalmente as membranas neovasculares sub-retinianas na degeneração macular relacionada a idade e na miopia). A exposição daqueles tecidos à luz infravermelha específica, que é seletivamente absorvida pelo pigmento injetado, provoca a fototerapia seletiva, que permite o tratamento dos tecidos circunjacentes, sem maiores lesões iatrogênicas.

O Brasil foi pioneiro no uso da indocianina verde na fototerapia macular seletiva através de técnica idealizada por Michel Farah, Costa e Cardillo. Nos EUA introduziu-se o uso da verterporfirina (Miller, Emidth e Gragoudas) e é possível que outros pigmentos possam ser disponibilizados, com funções específicas de tratamento de camadas ou de tecido alvo, como as membranas neovasculares sub-retinianas.

Hoje, no ano 2003, o tratamento a laser está limitado pela tecnologia, que não conseguiu controlar, ainda, o dano corioretiniano iatrogênico. O laser do futuro deve ser mais seletivo e menos agressivo aos tecidos retiniano e coróideo.

\section{Retinopatia Diabética}

No momento atual, a retinopatia diabética se destaca como um grande problema, sendo considerada uma das doenças com maior potencial cegante. A humanidade espera que o diabetes e suas conseqüências passem a compor os livros da história da medicina.

Em 1921, Banting isolou a Insulina, aumentando a sobrevida dos diabéticos. Com o aumento da sobrevida destes pa- cientes surgiram as complicações vasculares crônicas que afetam a árvore vascular, incluindo membros, rins, coração, cérebro e, principalmente, os olhos, podendo levar à cegueira. Já em 1926 se descrevia a evolução ruim da retinopatia diabética, com uma história natural desfavorável, tanto na sua forma caracterizada pelo edema macular, levando a extensos infiltrados difusos no pólo posterior, quanto na forma proliferativa, com o conseqüente descolamento tracional da retina, extensas áreas de fibrose e hemorragia vítrea. E, em 1940, foi descrita por Duke Elder como a maior causa de cegueira irreversível em populações economicamente ativas, afirmação que é válida até os dias de hoje.

Um primeiro tratamento da retinopatia diabética consistiu na ablação seletiva da pituitária, logo abandonado. No final dos anos 60 teve início a panfotocoagulação no tratamento da doença. Logo a seguir iniciaram-se, nos anos 70, grandes estudos clínicos realizados nos EUA e na Europa, que apontaram melhores resultados no curso da retinopatia diabética quando tratada com fotocoagulação, se comparados à evolução natural da doença. Nos Estados Unidos, destacam-se os estudos DRS (entre 1971 e 1978), DRVS (1976 a 1983), ETDRS (entre 1980 e 1989) e o DCCT (entre 1983 e 1989). Na Europa foi realizado o mais longo dos estudos, o UKPDS, iniciado em 1981 e terminado recentemente, em 1998. Ressaltam-se os resultados do DRS, que estabeleceu a validade definitiva da fotocoagulação na retinopatia diabética, e o ETDRS, que definiu os conceitos em uso na classificação e fotocoagulação na retinopatia diabética, principalmente do edema macular.

Através da fotocoagulação, na retinopatia diabética proliferativa, é possível a destruição das áreas isquêmicas e das áreas de neovasos. Entretanto, apesar do tratamento a laser, em $25 \%$ dos casos ocorre a hemorragia vítrea, associada, ou não, ao descolamento tracional de retina, levando à necessidade de vitrectomia, em casos de gravidade extrema, para a recuperação anatômica e de parte da função (Figura 6).

O objetivo principal do tratamento em presença de edema macular diabético são as micro-anormalidades vasculares intra-retinianas, visando o controle da exsudação e a reabsorção dos infiltrados na mácula. O laser apresenta resultados positivos em cerca de 50\% dos casos. Descrevemos, em 1983, a tração vítreo-macular como uma das causas do insucesso do

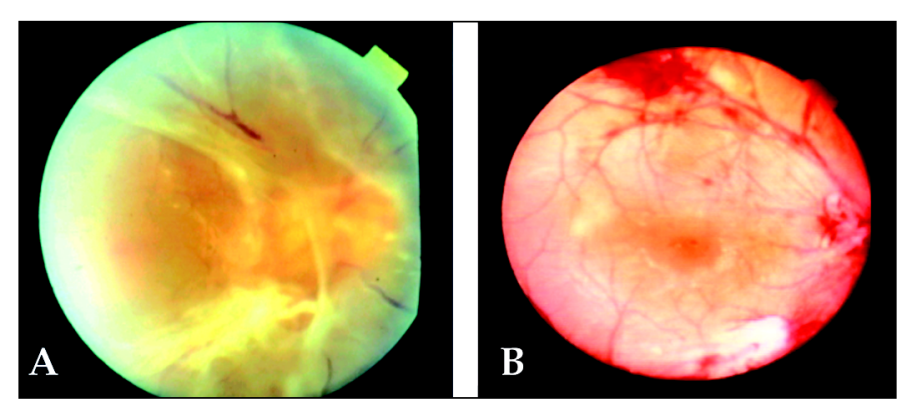

Figura 6 - Olho Direito. Retinopatia diabética proliferativa com descolamento de retina tracional. A) Pré vitrectomia; B) Pós vitrectomia. Note remoção de áreas de fibrose e reaplicação da retina 
tratamento a laser do edema macular diabético persistente. A vitrectomia tem se mostrado uma boa solução, quando, durante a cirurgia, se faz a remoção da hialóide que, geralmente, está aderida ao pólo posterior. Atualmente faz-se também a remoção da membrana limitante interna. Este tratamento apresenta alguns bons resultados, levando à absorção lenta e progressiva dos exsudatos existentes (Figura 7). Infelizmente a melhora anatômica observada, nem sempre, corresponde à melhora visual almejada.

Múltiplas fontes de estudos encaminham a atribuição da lesão básica do endotélio vascular, a alteração da permeabilidade e do estímulo de crescimento vascular a uma origem inflamatória. Assim, iniciou-se, em 2000, a utilização de corticosteróides intra-vítreos (triancinolona) no tratamento do edema macular diabético persistente com bons resultados anatômicos e funcionais (Figura 8). Recentemente tem sido também bastante empregada a injeção intra-vítrea de triancinolona no tratamento da membrana neovascular sub-retiniana.

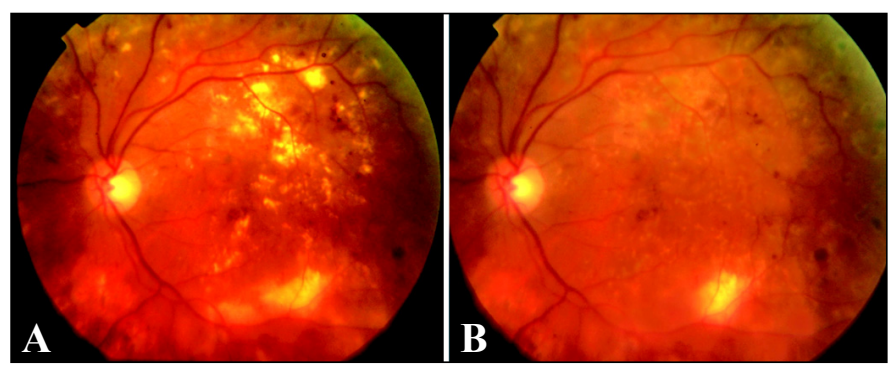

Figura 7 - Edema Macular Diabético Persistente. A) Pré vitrectomia B) 19 meses pós vitrectomia. Note reabsorção dos exsudatos restando pequeno depósito inferior à mácula e despigmentação peri-macular
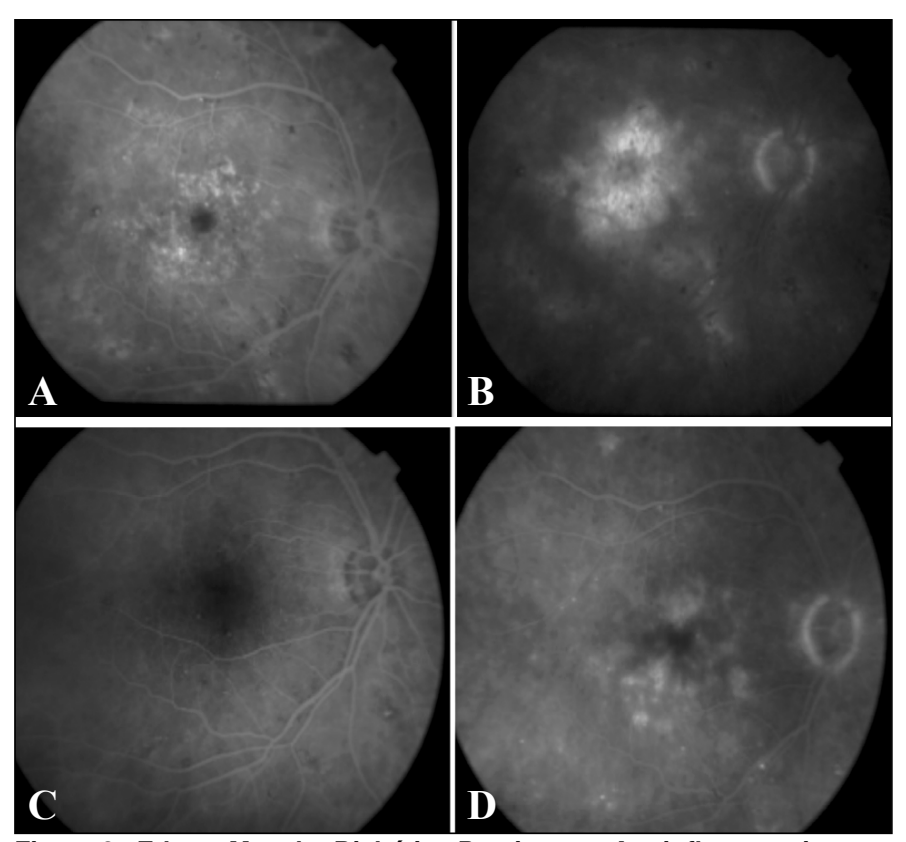

Figura 8 - Edema Macular Diabético Persistente. Angiofluoresceinografia: Fases inicial e tardia. A e B) Pré injeção de triancinolona; C e D) 8 semanas pós injeção. Note diminuição importante do edema macular
Concentram-se neste momento vários estudos, com técnicas diferenciadas, principalmente na área da biologia molecular, buscando formas terapêuticas satisfatórias no combate às principais causas de doenças com alterações vasculares. Um exemplo desta linha de pesquisa é a descrição do papel dos antagonistas, principalmente, do fator de crescimento vascular endotelial (VEGF) em grande variedade de pesquisas em animais e em humanos.

Assim, a história mostra, nos dias atuais (2003) uma grande convergência nas metas estabelecidas para o tratamento da retinopatia diabética e da forma exsudativa da degeneração macular relacionada à idade, que buscam a abordagem nas vertentes da prevenção, da intervenção e da restauração. O quadro 1 resume as principais linhas de investigação da atualidade.

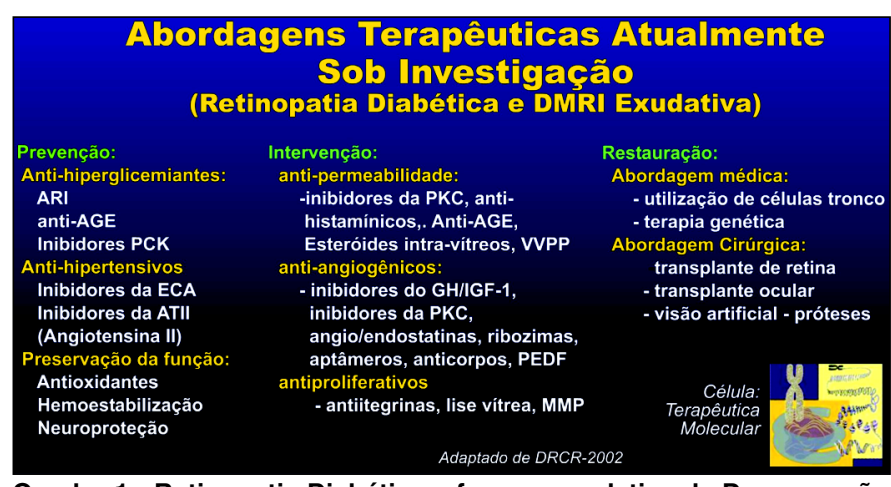

Quadro 1 - Retinopatia Diabética e forma exsudativa da Degeneração Macular Relacionada à Idade (Adaptado de DRCR 2002)

Nos tratamentos de prevenção e intervenção a meta principal é o bloqueio da cascata de alterações que lesam o interior das células, através das lesões nas organelas intra-celulares. Pretende-se, desta maneira, conseguir o bloqueio de eventos danosos utilizando agentes medicamentosos que atuarão preventivamente no espaço extra-celular ou dentro da própria célula. Percebe-se, portanto, que a maioria das doenças vasculares (retinopatia diabética e degeneração macular relacionada à idade na sua forma exsudativa) e outras como as tromboses venosas, a retinopatia do prematuro, encontrarão na terapêutica molecular o grande futuro no seu tratamento.

O quadro 2 visualiza o esforço feito na compreensão e na abordagem das complicações advindas da sobrevivência do diabético e de seu sofrimento vascular, durante quase meio século. Introduzido em 1968 o uso do laser e da vitrectomia, iniciou-se efetivamente o tratamento da doença. Hoje, passados 35 anos, as duas formas terapêuticas, juntas, alcançam apenas $60 \%$ de sucesso na prevenção da perda visual severa (melhora ou estabilização visual). Alentadoramente, se incluirmos na avaliação do sucesso, a prevenção da cegueira total, este índice se eleva para mais de $90 \%$.

A partir do ano 2000, o uso da triancinolona e dos antiangiogênicos (ainda em processo de investigação) gera a es- 


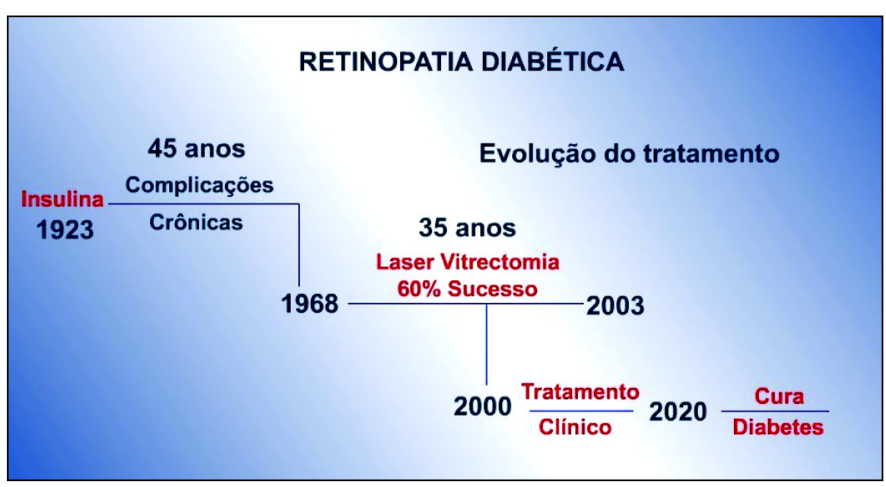

Quadro 2 - Retinopatia Diabética

perança de que no ano 2020 esteja disponível o tratamento clínico das complicações crônicas do diabetes, especificamente da retinopatia, e que a próxima década traga a cura do diabetes.

\section{Degeneração Macular Relacionada à Idade}

A degeneração macular relacionada à idade (DMRI) foi descrita primeiramente por Oeller, em 1903, portanto, há cem anos. Em 1926, Junius e Kunt a apontaram como a principal causa de cegueira legal em pessoas com mais de 55 anos de idade. Registram-se hoje, no Brasil, cerca de cinco milhões de indivíduos com DMRI, nas suas duas principais formas de manifestação: a forma seca (presença de drusas e alterações pigmentares no pólo posterior) e a forma exsudativa, com efeitos deletérios e evolução ruim (membrana neovascular sub-retiniana associada a formação de cicatriz fibrovascular e a processo sero-hemorrágico da retina neuro-sensorial no pólo posterior.

A angiofluoresceinografia foi inicialmente utilizada para o estudo da forma exsudativa da doença, evidenciando membranas neovasculares sub-retinianas bem definidas (Figura 9) em cerca de 13\% dos casos. Em 1997, mostramos que a metade dos $87 \%$ de casos de membranas consideradas ocultas quando analisadas pela angiofluoresceinografia podem se revelar como bem definidos, através da indocianina verde (Figura 10).

Espera-se um grande avanço no tratamento da DMRI, com o uso de anti-oxidantes e vitaminas. O projeto Age Related Eye Disease Study (AREDS), desenvolvido nos EUA, avaliou, em estudos controlados durante cerca de seis anos, a eficácia de tratamentos com anti-oxidantes (vitaminas C, E e beta caroteno), zinco e cobre. A conclusão mostrou ausência de benefícios na fase inicial da doença (pacientes com poucas drusas); porém na forma intermediária (presença de microdrusas cuticulares no pólo posterior, uma ou mais drusas grandes e múltiplas algodonosas em todo pólo posterior) ou unilateral avançada, houve significativa redução no risco de doença avançada, com o uso de anti-oxidantes e zinco.

Nos anos 80 se iniciou o tratamento da forma exsudativa preconizando-se o uso do laser de argônio verde puro. Publicamos, em 1985, casos de membrana bem definida em que o tratamento com laser levou à formação de cicatriz atrófica
(Figura 11). Em 1999, mostramos 50\% de sucesso anatômico e funcional no tratamento com laser definido pela indocianina verde. Entretanto, registrava-se recorrência da membrana neovascular sub-retiniana em 50\% dos casos de MNSR bem definida, tratados com o uso diagnóstico da fluoresceinografia ou da indocianina verde (Figura 12).

Para compensar os resultados ruins alcançados com o tratamento a laser térmico, a médio e longo prazos, utilizou-se a translocação macular, cirurgia que estava associada a inúmeras complicações, decorrentes da manipulação cirúrgica no deslocamento induzido da retina na sua metade temporal, trazendo conseqüências como descolamento de retina, proliferação vítreo-retiniana e hipotonia.

O controle cirúrgico (remoção) do crescimento da membrana neovascular sub-retiniana utiliza técnicas específicas de vitrectomia via pars-plana, hoje indicada, principalmente, em pacientes jovens com membranas no feixe papilo macular.

A introdução da fototerapia seletiva ou terapia fotodinâ-

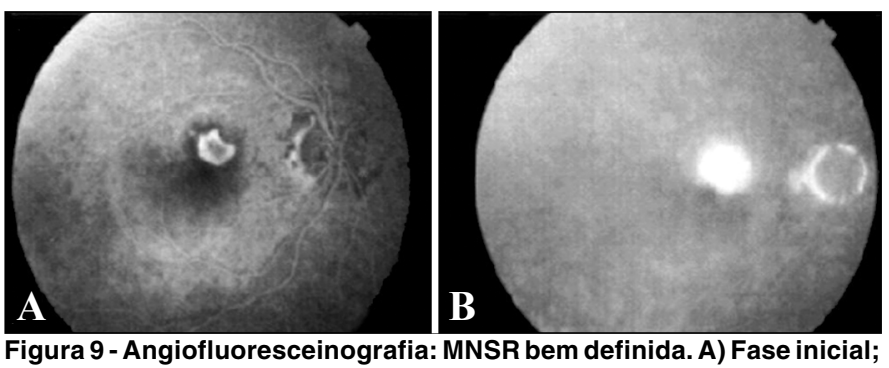

B) Fase tardia
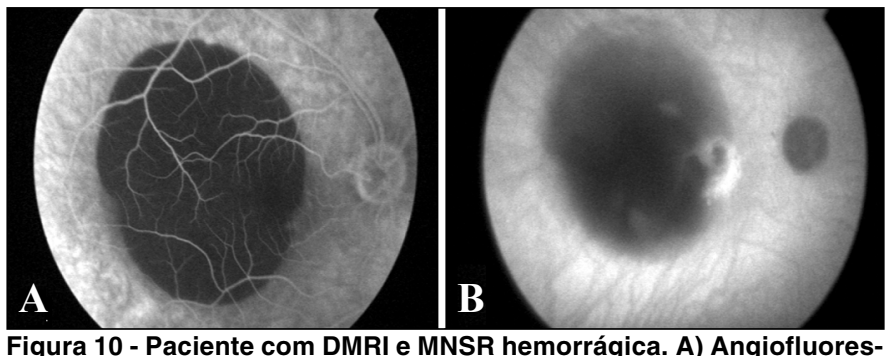

Figura 10 - Paciente com DMRI e MNSR hemorrágica. A) Angiofluoresceinografia: Note bloqueio total da MNSR; B) Videoangiografia Digital com Indocianina Verde: MNSR bem definida nasal inferior
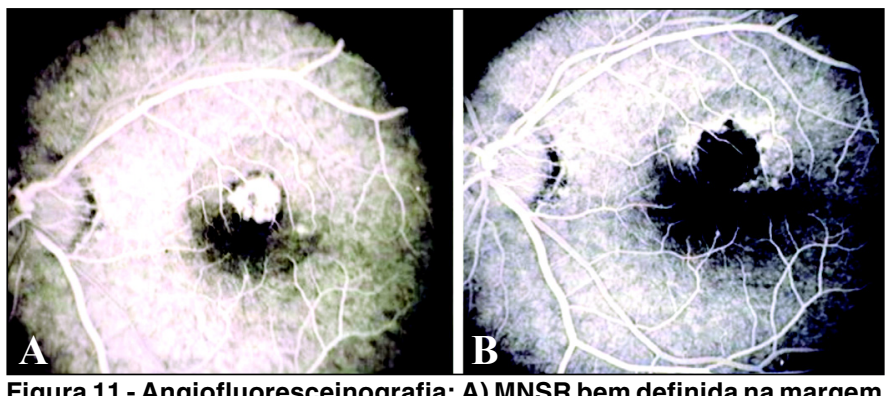

Figura 11 - Angiofluoresceinografia: A) MNSR bem definida na margem temporal superior da fóvea; B) Bloqueio pós tratamento com laserterapia (Ávila et al, 1985) 

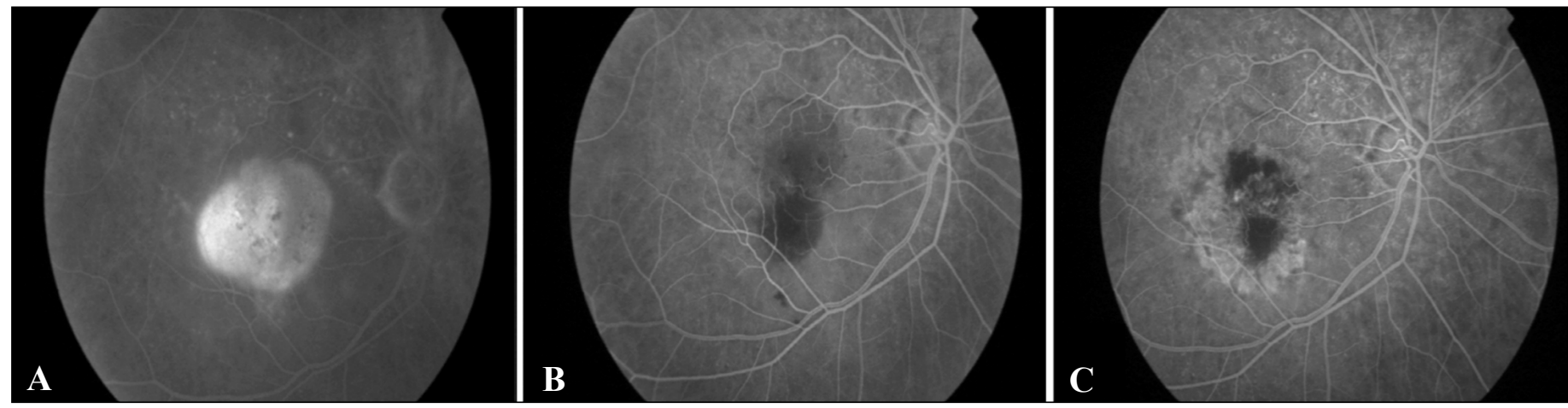

Figura 12 - DMRI. Angiofluoresceinografia: A) Pré tratamento descolamento do epitélio pigmentar (DEP) na mácula; B) Um mês pós fotocoagulação: bloqueio da membrana neovascular sub-retiniana (MNSR) e desaparecimento do DEP. C) Seis meses pós tratamento: recorrência da MNSR.

mica (PDT) permitiu a inclusão de novos pacientes no rol daqueles tratáveis com sucesso (estabilização ou melhora visual) principalmente naqueles portadores de membrana neovascular subfoveal. Infelizmente, a técnica está também associada à persistência ou recorrência da MNSR, tendo a necessidade de mais de uma sessão (média 3,2) para controle da MNSR. Algumas destas recorrências, as extra-foveais ou marginais podem ser tratadas com laser convencional (Figura 13). A técnica está em evolução, exigindo, pela rapidez das descobertas em estudos controlados, a atualização permanente. A introdução deste método inovador obriga, ainda, o constante refazer das linhas de raciocínio clínico com fluxograma para auxílio nas decisões.

Assim, recomendamos um fluxograma ou algoritmo para tratamento da MNSR na degeneração macular relacionada à idade (quadro 3) levando-se em consideração a localização da lesão, sua composição angiofluoresceinográfica, a progressão recente da doença, o tamanho da MNSR e a acuidade visual. Em caso de recorrência na fóvea recomenda-se nova terapia fotodinâmica e na recorrência extrafoveal deve-se considerar o uso do laser térmico.

O tratamento da DMRI em sua forma exsudativa também, a exemplo do edema macular diabético, pode ser feito com injeção de triancinolona intra-vítrea, principalmente em casos de membrana neovascular sub-retiniana com sangramento recente, envolvendo área maior do pólo posterior (Figura 14). Infelizmente o efeito da triancinolona intra-vítrea se perde com o tempo, exigindo múltiplas aplicações. Estamos experimentando, aparentemente com bons resultados na prevenção de recorrências, o uso concomitante de terapia fotodinâmica e injeção de triancinolona, que parece concorrer para melhora do processo de controle do estimulo angiogênico.

$\mathrm{O}$ acompanhamento pós-laserterapia térmica ou terapia fotodinâmica ainda não está sistematizado, sendo fundamental a medida da acuidade visual, a verificação de metamorfopsias, a biomicroscopia da retina e, em alguns casos, vigilância através de angiofluoresceinografia, indocianina verde, RTA e OCT.

A angiofluoresceinografia, após terapia fotodinâmica, pode mostrar pequenos canais vasculares permeáveis, possíveis indicadores de doença em atividade, embora o acompanhamento de alguns casos, por mais de um ano, tenha mostrado que permaneceram estáveis e com boa visão (Figura 15). Percebe-se, portanto, a necessidade do uso de outras técnicas, quando existe vazamento após o primeiro mês pós tratamento.

A indocianina verde, como demonstramos em 1997, é um ótimo método de seguimento após laser térmico, mostrando sua utilidade quando se registra, pela fluoresceinografia, suspeita de recorrência ou persistência em casos com aparente
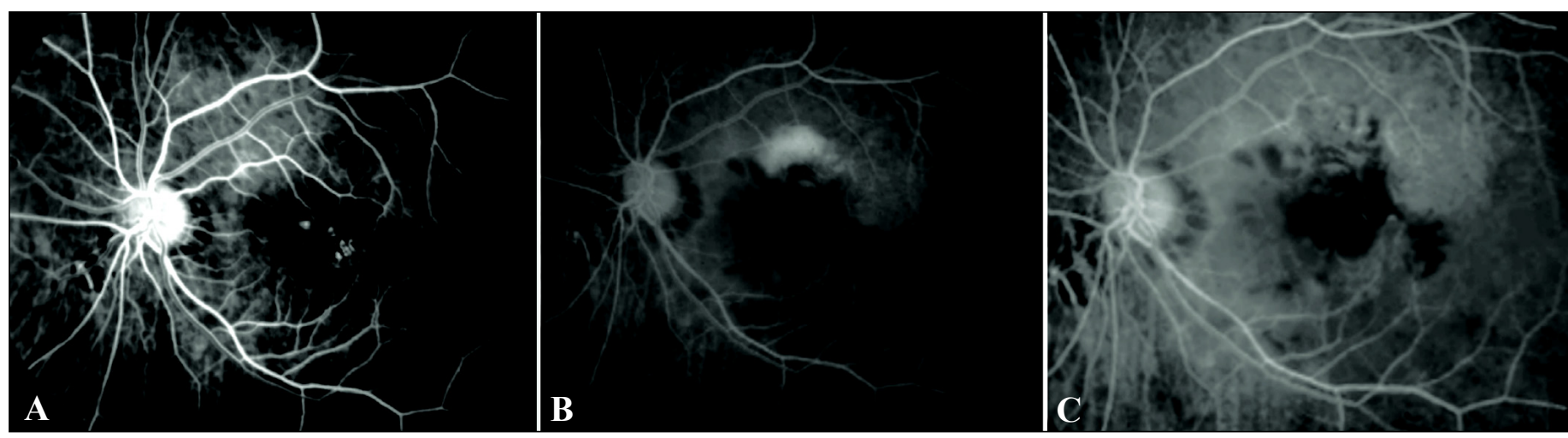

Figura 13 - DMRI. Angiofluoresceinografia: A) Pré terapia fotodinâmica. MNSR bem definida na fóvea; B) Três meses pós tratamento: bloqueio na área tratada e recorrência extra-foveal superior (marginal); C) Pós tratamento da lesão marginal com laser térmico 


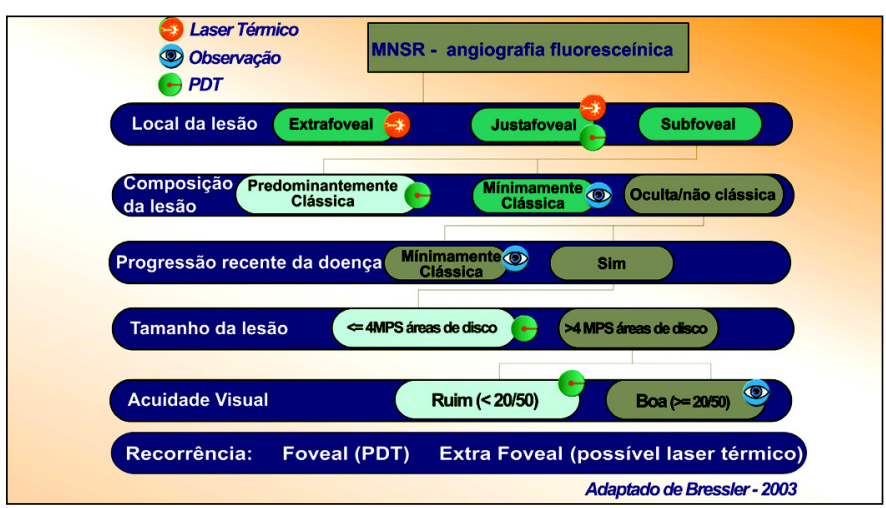

Quadro 3 - Degeneração Macular Relacionada à Idade. Algoritmo de tratamento

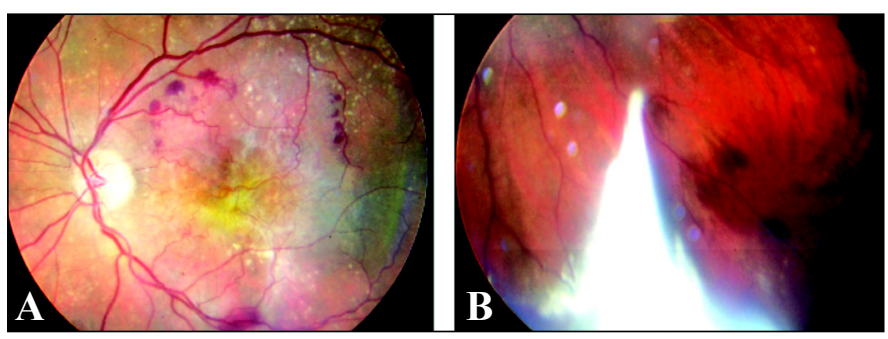

Figura 14 - DMRI exsudativa pré triancinolona. A) MNSR ocupando grande área do pólo posterior; B) Depósito de triancinolona nos quadrantes inferiores
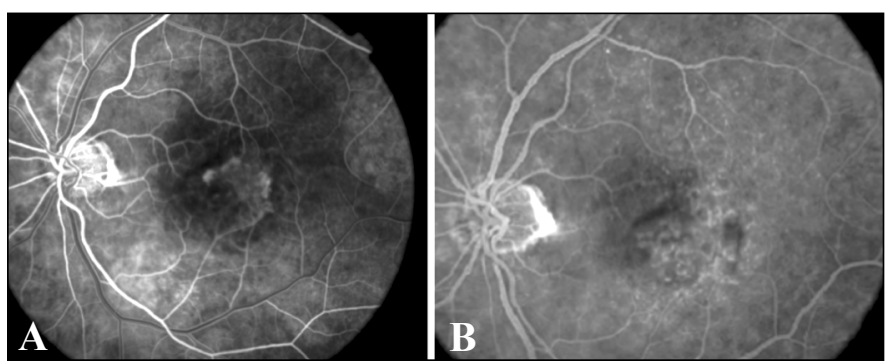

Figura 15 - DMRI: Angiofluoresceinografia. A) MNSR sub-foveal pré Terapia Fotodinâmica (PDT). B) 14 meses pós tratamento. Note "staining" tardio, sem evidência de MNSR em atividade

bloqueio ou inversamente quando existe somente vasculite térmica e ausência de MNSR ativa (Figura 16). Está em estudo a sua utilidade no acompanhamento pós-terapia fotodinâmica.

Em alguns casos, como no acompanhamento do edema macular pós tratamento, o RTA pode ser útil.

O OCT apresenta bom percentual de predição no acompanhamento de casos tratados com terapia fotodinâmica, sendo extremamente útil na visualização da diminuição do líquido sub e intra-retiniano e na medida da espessura da MNSR na fóvea.

Apesar dos tratamentos a laser com e sem seletividade, o grande futuro do tratamento da MNSR está na biologia molecular, já que múltiplos mecanismos influenciam as organelas celulares, induzindo a proliferação e o aumento da permeabilidade, exigindo, portanto, o controle farmacológico da proliferação vascular das células (quadro 1)
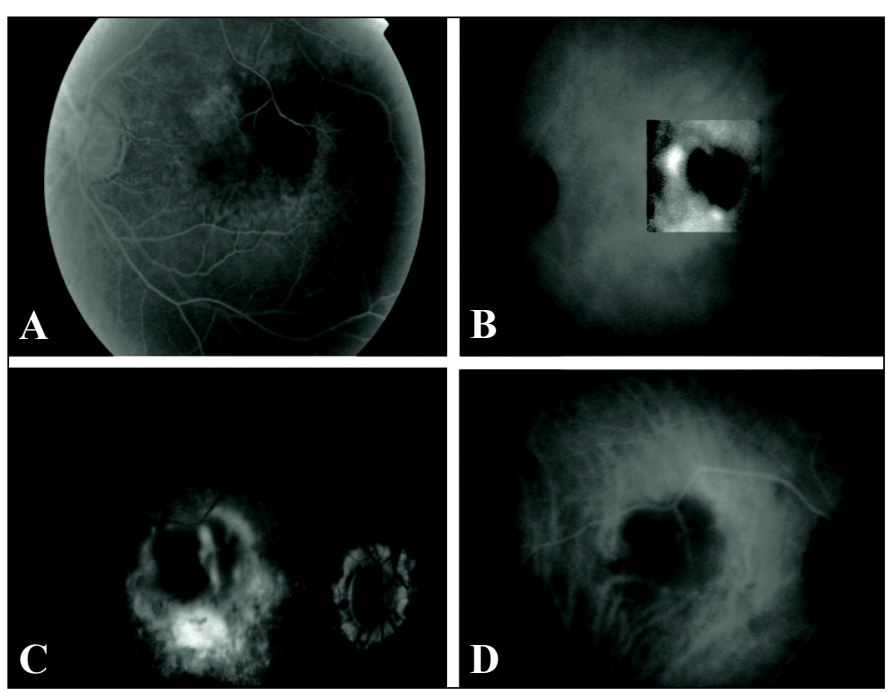

Figura 16. Dois casos de MNSR pós laserterapia. Caso 1 - Olho Esquerdo: A) Angiofluoresceinografia: Aparente bloqueio total da área tratada; B) Videoangiografia Digital com Indocianina Verde: persistência de MNSR nas margens inferior e nasal superior. Caso 2 - Olho Direito: C) Angiofluoresceinografia: vasculite térmica no centro da lesão e suspeita de MNSR na margem inferior da área tratada; D) Videoangiografia Digital com Indocianina Verde: ausência de MNSR

As investigações multicêntricas internacionais (que incluem centros brasileiros) sobre o uso dos anti-angiogênicos são promissores, destacando-se os relativos ao uso de corticóides peri-oculares modificados (Anecortave) e anti-angiogênico (Macugen). Em futuro próximo, outros estudos como o do Rhu fab, poderão mostrar a utilidade de cada um ou da combinação de anti-angiogênicos no tratamento da forma neovascular da DMRI.

O quadro 4 mostra a seqüência histórica da evolução do conhecimento sobre a DMRI, durante 100 anos: de 1903 a 1926 foram feitas a observação e a descrição da história natural da doença, passando-se 42 anos sem que se propusesse qualquer tipo de tratamento. E desde 1968, com o advento das mudanças do laser, até o ano 2003, somente se conseguiu 50\% de sucesso na prevenção da perda visual severa. É muito pouco! Espera-se que a farmacoterapia, colocada em grande evidência no início deste milênio, possa trazer, até o ano 2020, o controle farmacológico do crescimento da membrana neovascular sub-retiniana.

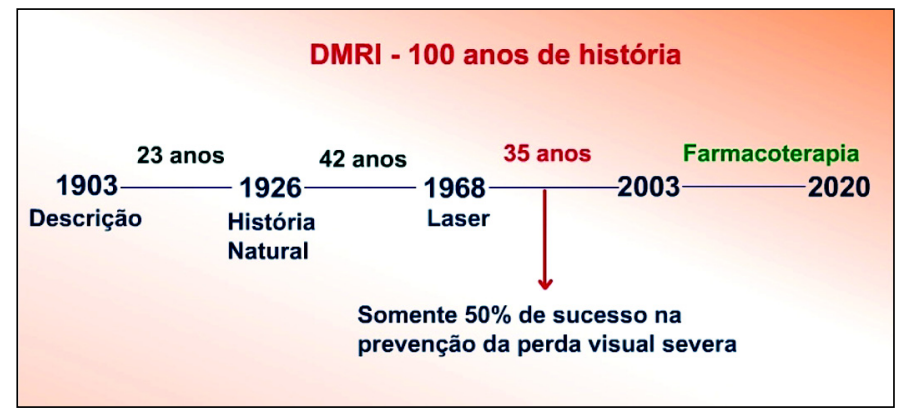

Quadro 4 - Degeneração Macular Relacionada à Idade 


\section{Descolamento de Retina}

A descoberta do oftalmoscópio, em 1851, trouxe grandes avanços e, dois anos depois, já se descrevia o primeiro buraco retiniano. Entretanto, somente 72 anos depois, o imortal e célebre Jules Gonin propôs o bloqueio do buraco retiniano, através da Ignipuncture, cirurgia equivalente a um termocautério, obtendo, já naquela época, cerca de $50 \%$ de sucesso nos casos operados. Mais tarde, Custodis introduziu a cirurgia com introflexão escleral, mostrando a necessidade do tamponamento externo das roturas, procedimento em uso até os dias atuais. Com a possibilidade de observação binocular através do oftalmoscópio indireto e o auxílio da depressão escleral, ambas introduzidas por Charles Schepens, em 1947, e popularizadas nos anos 50, passou-se à terceira etapa no tratamento do descolamento primário de retina, onde o exame detalhado da retina e do vítreo, e a localização das roturas através da observação da periferia retiniana, possibilitou o tratamento com retinopexia e tamponamento externo adequado de cada lesão.

Em 1962, Lincoff introduziu as esponjas de silicone e popularizou o uso da crioterapia. A quarta etapa no tratamento do descolamento de retina se caracteriza pela introdução do tamponamento interno, inicialmente com ar, técnica introduzida em 1938 por Rosengren, sem grande repercussão. Até que, em 1971, Norton usou os gases expansivos intra-operatórios, e, em 1984 e 1985 Hilton e Grizzard, nos EUA, e Dominguez, na Espanha, desenvolveram a técnica de pneumo-retinopexia primária, que consiste na colocação de gás dentro do olho, para que seja feito o tamponamento interno da rotura e a reaplicação da retina. O tamponamento interno durante a vitrectomia pode utilizar, além dos gases expansivos, o moderno óleo de silicone, introduzido por Scott em 1975.

Outra grande evolução (quinta etapa) é a introdução da vitrectomia, em 1971, por Robert Machemer. Em 1972 O’Malley respondeu por um dos grandes avanços da vitrectomia, dividindo a sonda em três partes: a infusão, a iluminação e os instrumentos ativos (vitreófago, por exemplo), até então concentrados em um único instrumento, trabalhando com três esclerotomias. Um grande avanço na vitrectomia se deve à introdução dos microscópios com os movimentos de $\mathrm{X}$, Y e
Zoom.Tais conquistas são hoje incorporadas à técnica, minimizando-se às vezes, a sua importância no progresso da ciência. Registrou-se também um grande avanço na instrumentação intra-ocular com múltiplas pinças e tesouras e na introdução do endolaser durante a cirurgia.

A sexta e atual etapa na história do tratamento do descolamento de retina teve seu início em 1989, quando Stanley Chang introduziu o uso do perfluorcarbono (PFC), modificando a cirurgia da vitrectomia, principalmente quando empregada para o tratamento do descolamento de retina, já que possibilita a mobilização da retina no pólo posterior, e permite que a retina posterior seja reaplicada através do uso deste líquido (mais pesado do que a água). Esta tecnologia facilita o tratamento de rupturas gigantes e de casos com proliferação vítreo-retiniana grave (Figura 17).

Inicialmente, o PFC foi utilizado em casos graves de descolamento de retina, mas em 1997, mostramos, juntamente com Stanley Chang, nossa experiência com o produto em casos de descolamento de retina primário. A introdução de lente de grande angular trouxe grande avanço para a vitrectomia, possibilitando a realização de cirurgia através de pupilas mióticas, ou meios oculares de baixa transparência. A vídeoendoscopia permitiu o acesso às estruturas anteriores e a realização de cirurgia em casos em que a transparência está bloqueada.

Não existe um algoritmo ideal para a escolha da técnica cirúrgica no tratamento do descolamento de retina, podendose, entretanto, utilizar o fluxo mostrado no quadro 5 , baseado na complexidade do descolamento de retina, para chegar a um tratamento mais recomendável. Este algoritmo descreve as várias situações que levam à decisão sobre o uso da retinopexia pneumática, introflexão escleral ou vitrectomia via pars-plana.

O quadro 6 mostra a evolução do tratamento do descolamento de retina, como um dos grandes sucessos da história da oftalmologia. Atente-se para o fato de que nos primeiros 70 anos que se sucederam à descrição do buraco retiniano não se conseguiu nenhuma forma de tratamento e nos 80 anos subseqüentes (de 1923 a 2003) chegou-se a uma taxa de sucesso terapêutico de cerca de $98 \%$. Estamos assim, os oftalmologistas de hoje, apoiados nos ombros de gigantes como Gonin, Custodis, Schepens, Machemer, Stanley Chang, que desenvolveram todo o armamentário tecnológico disponível.
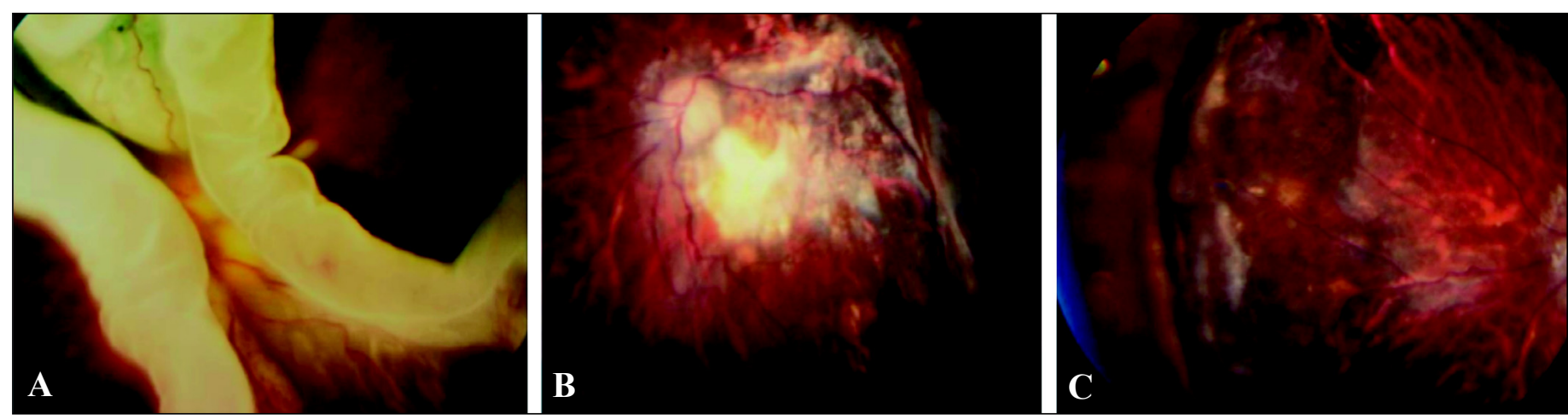

Figura 17 - A): Rotura gigante com extensão até próximo ao pólo posterior; B e C): Aspecto pós operatório. Note reaplicação do pólo posterior e da retina nasal 


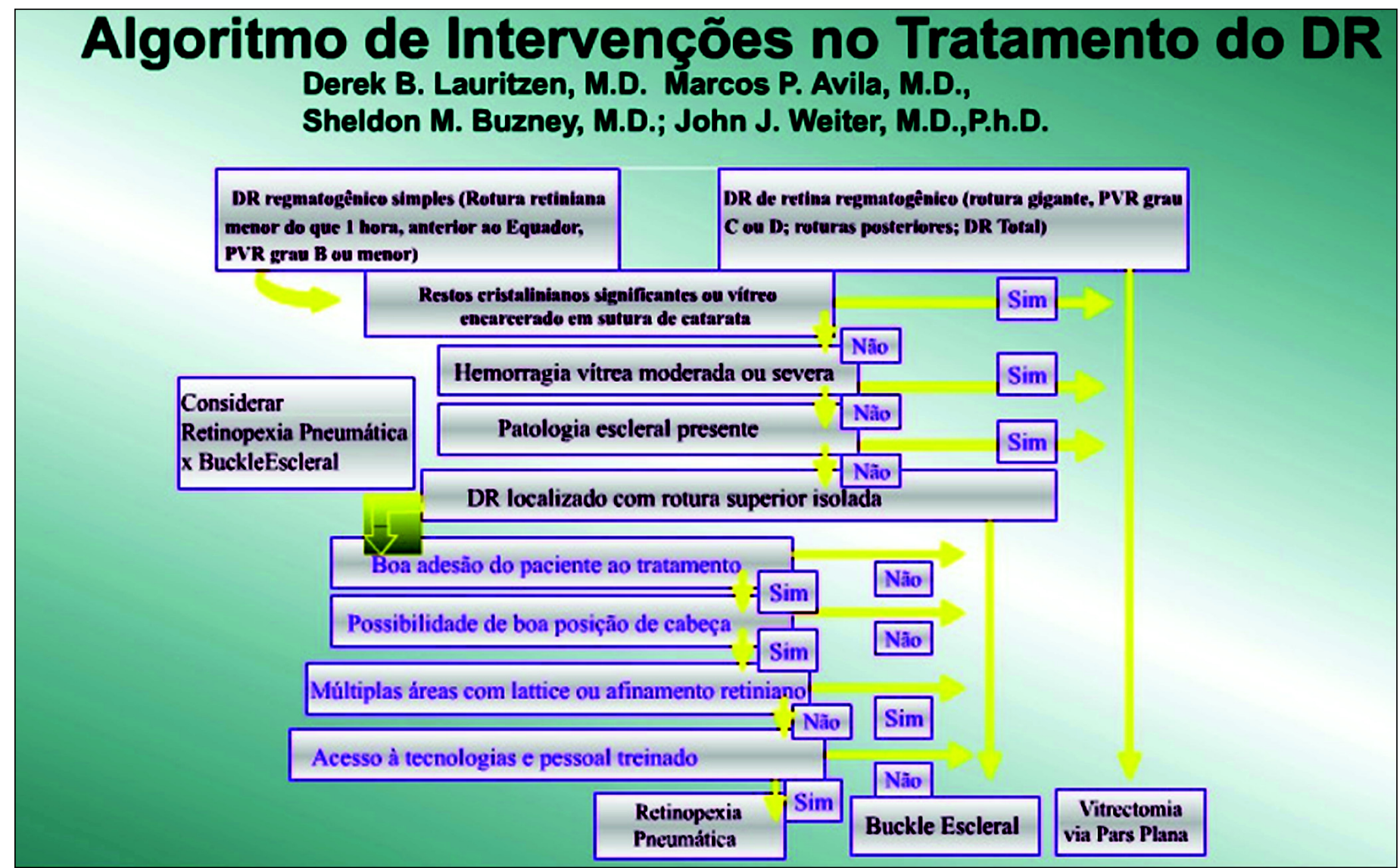

Quadro 5 - Descolamento de Retina. Algoritmo de Intervenções no Tratamento

\section{Buraco Macular}

Convém falar ainda sobre o buraco de mácula, doença que, inicialmente sem tratamento previsto, apresentou, em curtíssimo intervalo de tempo (de 1989 a 2003), taxa de $98 \%$ de sucesso terapêutico (quadro 7). Quando ainda residente, ao final dos anos 80, lia-se, no capítulo de retina, que não há tratamento efetivo para o buraco de mácula, que raramente evoluem para descolamento de retina, devendo ser meramente observados (livro General Ophthalmology, traduzido para o português pela editora da USP).

Em 1989, Wendel, na Academia Americana de Oftalmologia, apresentou dez casos de cirurgia de vitrectomia para tra-

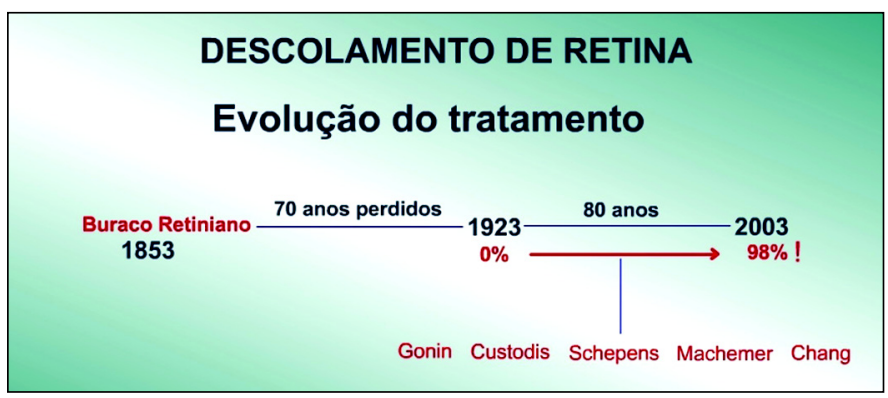

Quadro 6 - Descolamento de Retina. Evolução do Tratamento tamento do buraco de mácula. Intensas críticas questionavam a cientificidade da obra. O artigo foi publicado no Archives of Ophthalmology, em 1991, e em 1992 houve a confirmação anátomo patológica do sucesso de um dos casos.

Apontamos, em 1985, a tração ântero posterior como uma das causas do buraco macular, teoria que foi esquecida, para voltar a ser mencionada recentemente nos trabalhos do grupo de Laurence Yanuzzi, nos EUA. A fundamentação fisiopatológica pela indicação da cirurgia do buraco de mácula foi desenvolvida por Gass, em 1990, quando ele demonstrava tração tangencial na gênese da lesão.

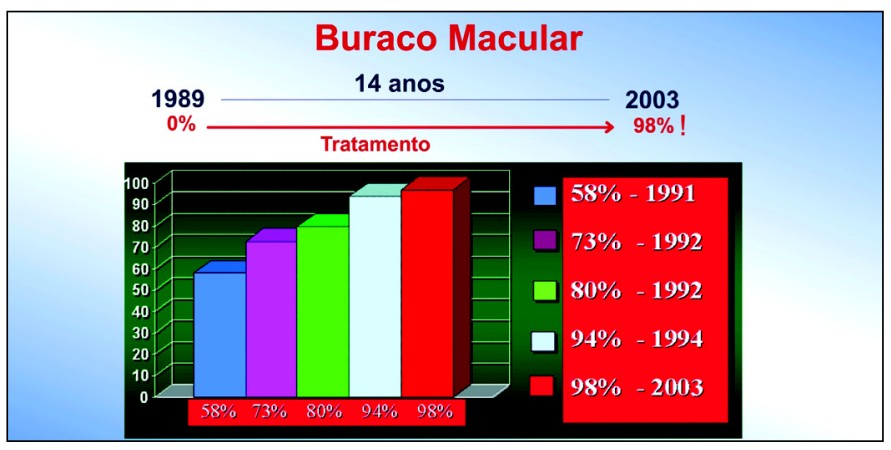

Quadro 7 - Buraco Macular. Evolução do Tratamento 
A técnica cirúrgica sugerida para o tratamento do buraco macular é relativamente simples consistindo na vitrectomia via pars-plana com separação mecânica da hialóide posterior, troca fluido gasosa, colocação de gás expansivo de longa permanência no olho e repouso com decúbito ventral durante a permanência do gás.

Foi dada grande ênfase aos adjuvantes, no início dos anos 90 (soro autólogo, TGF- $\beta$, plasma autólogo, trombina bovina, concentração autóloga de plaquetas, TGF- $\beta$ bovino e fibrogênio crio-precipitado), abandonados a partir da convicção de que o sucesso cirúrgico não dependia daqueles fatores. Iniciou-se, a seguir, a era do "peeling" da membrana limitante interna, sem e com o uso de corante. O corante utilizado (a indocianina verde) favorece sobremaneira a remoção da membrana limitante interna, permanecendo, entretanto, a dúvida sobre seu uso, devido a um possível efeito fototóxico ou mesmo fotodinâmico na interface vítreo-macular. Entretanto, as evidências indicam que a remoção da membrana leva a melhores resultados finais.

\section{Agradecimentos}

Apresento meus agradecimentos a todos os que participaram da elaboração deste trabalho: Doutoras Lívia Souza e Ericka Campos Freitas; Doutores José Ricardo Costa, Humberto Borges, David Isaac, Alexandre Taleb e, em especial, Dr. Arnaldo Cialdini, que fazem parte da equipe de retina do $\mathrm{CBCO}$ e da Universidade Federal de Goiás e as professoras Adriana Parada e Josete Parada. Faço um agradecimento especial ao Doutor Charles Schepens, meu mentor, com quem tive oportunidade de trabalhar durante cinco anos na Retina Foundation, em Boston, USA, figura fundamental na formação dos meus princípios éticos e no despertar de meu espírito científico.

Finalizo com textos retirados do trabalho que fizemos publicar em co-autoria com o Doutor Harley Bicas, como editorial recente dos Arquivos Brasileiros de Oftalmologia.

Ao Conselho Brasileiro de Oftalmologia, uma das mais importantes entidades médicas do País, apresento os meus agradecimentos pelo prestigioso convite para apresentar sua Conferência CBO 2003, anexada na íntegra, na forma de CD-ROM .

\title{
X SIMPÓSIO INTERNACIONAL DE CÓRNEA E LENTES dE CONTATO
}

\section{6 e 27 de marge de 2.004}

\section{PROMOÇÃ O: Seminário Oftalmológico da UNICAMP}

\author{
INFORMAÇÕES: Tels.: (19) 3788-7337/3788-7110 c/ Ana Paola ou \\ (19) 3078-1899 c/ Kátia
}

